\title{
Phase 1 combination study of Eribulin mesylate with trastuzumab for advanced or recurrent human epidermal growth factor receptor 2 positive breast cancer
}

\author{
Hirofumi Mukai • Toshiaki Saeki • Ken Shimada • \\ Yoichi Naito • Nobuaki Matsubara • Tadashi Nakanishi • \\ Hiroshi Obaishi • Masayuki Namiki • Yasutsuna Sasaki
}

Received: 9 July 2014 / Accepted: 8 September 2014 / Published online: 23 September 2014

(C) The Author(s) 2014. This article is published with open access at Springerlink.com

\begin{abstract}
Summary Eribulin mesylate (Halaven ${ }^{\circledR}$ ) is a novel inhibitor of microtubule dynamics that has demonstrated a survival benefit in patients with locally recurrent or metastatic breast cancer who previously received at least two chemotherapeutic regimens including an anthracycline and a taxane. Although trastuzumab is indicated for patients with human epidermal growth factor receptor 2 positive (HER2+) breast cancer, a phase 1 study to evaluate tolerability/safety of eribulin mesylate with trastuzumab has not been conducted. Therefore, a study of eribulin mesylate in combination with trastuzumab was conducted to evaluate dose limiting toxicity (DLT), tolerability/safety, pharmacokinetics (PK), and efficacy and to
\end{abstract}

Presented in poster format at the European Cancer Congress 2013, Amsterdam, the Netherlands, 27 September-1 October 2013.

H. Mukai $(\bowtie) \cdot$ Y. Naito $\cdot$ N. Matsubara

Department of Breast and Medical Oncology,

National Cancer Center Hospital East,

6-5-1 Kashiwanoha, Kashiwa, Chiba 277-8577, Japan

e-mail: hrmukai@east.ncc.go.jp

T. Saeki

Department of Breast Oncology Cancer Center, International

Medical Center Saitama Medical University, 1397-1 Yamane,

Hidaka, Saitama 350-1298, Japan

K. Shimada

Department of Internal Medicine, Showa University Northern

Yokohama Hospital, 35-1 Chigasaki-chuo, Tsuzuki-ku, Yokohama,

Kanagawa 224-8503, Japan

T. Nakanishi $\cdot$ H. Obaishi $\cdot$ M. Namiki

Eisai Co., Ltd,

4-6-10 Koishikawa, Bunkyo-ku, Tokyo 112-8088, Japan

\section{Y. Sasaki}

Division of Medical Oncology-Department of Medicine,

Showa University School of Medicine, 1-5-8 Hatanodai,

Shinagawa-ku, Tokyo 142-8666, Japan estimate the recommended dose in Japanese patients with advanced or recurrent HER2+ breast cancer. Eribulin mesylate $\left(1.4 \mathrm{mg} / \mathrm{m}^{2}\right)$ was administered on days 1 and 8 of every 3 week cycle. Trastuzumab was administered with a $4 \mathrm{mg} / \mathrm{kg}$ loading dose followed by $2 \mathrm{mg} / \mathrm{kg}$ weekly doses or with an $8 \mathrm{mg} / \mathrm{kg}$ loading dose followed by $6 \mathrm{mg} / \mathrm{kg}$ tri-weekly doses. A total of 12 patients (six for each regimen) received eribulin mesylate and trastuzumab. No DLT was observed and the recommended dose of eribulin mesylate in combination with trastuzumab was estimated as $1.4 \mathrm{mg} / \mathrm{m}^{2}$. Common adverse events were neutropenia, leukopenia, anaemia and alopecia. This combination therapy was well tolerated and the neutropenia observed was manageable. No PK drug-drug interaction between eribulin and trastuzumab was observed. Since a transient ejection fraction decreased was observed in two patients, cardiac function should be routinely assessed in patients receiving the combination therapy of eribulin mesylate with trastuzumab (ClinicalTrials.gov Identifier: NCT01432886).

Keywords Eribulin mesylate $\cdot$ HER2 positive breast cancer . Japanese patients · Phase 1 study · Trastuzumab

\section{Introduction}

Overexpression of human epidermal growth factor receptor 2 (HER2) occurs in approximately 25 to $30 \%$ of breast cancers and is associated with a poor prognosis $[1,2]$. Trastuzumab is a humanized IgG1 kappa monoclonal antibody that selectively binds with high affinity to the extracellular domain of the HER2 protein. The studies of weekly trastuzumab monotherapy $(4 \mathrm{mg} / \mathrm{kg}$ loading dose followed by $2 \mathrm{mg} / \mathrm{kg}$ weekly) and combination with paclitaxel was active, well tolerated and prolonged survival in patients with HER2+ metastatic breast cancer [3-5]. Also, 
comparison of tri-weekly trastuzumab $(8 \mathrm{mg} / \mathrm{kg}$ loading dose followed by $6 \mathrm{mg} / \mathrm{kg}$ tri-weekly dose) with weekly trastuzumab has shown comparable results in both monotherapy and combination therapy with paclitaxel $[6,7]$. The combination therapy of a tubulin-targeted drug and trastuzumab appeared to have a superior antitumor effect and a well-tolerated safety profile in the treatment of HER2 + breast cancer [5, 7-9].

Eribulin mesylate, a non-taxane microtubule dynamics inhibitor, is a structurally simplified synthetic analog of the marine natural product halichondrin $\mathrm{B}$. The inhibitory effects of eribulin on microtubule dynamics lead to $\mathrm{G}_{2} / \mathrm{M}$ cell-cycle blocks, disruption of normal mitotic spindle formation, and prolonged mitotic blockage followed by apoptotic cell death $[10,11]$.

A phase 1 study has been completed in Japanese patients with solid tumors to evaluate the safety and pharmacokinetics (PK) of eribulin mesylate administration on days 1 and 8 of a 21-day cycle. Dose-limiting toxicities (DLTs) were neutropenia/febrile neutropenia, and the recommended dose of eribulin mesylate was determined as $1.4 \mathrm{mg} / \mathrm{m}^{2}$ [12]. Based on the results of this phase 1 study in Japan, a phase 2 study was conducted to evaluate the efficacy and safety of eribulin mesylate in patients with locally advanced or metastatic breast cancer previously treated with anthracycline and taxane. Eribulin mesylate demonstrated antitumor activity with an objective response rate (ORR) of $21.3 \%$ (17/80 patients) and a manageable safety profile [13]. This study supported the previous phase 2 study of eribulin mesylate that demonstrated its antitumor activity and safety profile in extensively pretreated breast cancer patients $[14,15]$.

In a randomized phase 3 study of patients with locally recurrent or metastatic breast cancer who previously received at least two chemotherapeutic regimens including an anthracycline and a taxane, the efficacy and safety of eribulin mesylate $\left(1.4 \mathrm{mg} / \mathrm{m}^{2}\right.$, days 1 and 8 of a 21-day cycle) were compared with the treatment of the physician's choice (TPC). Overall survival (OS) was statistically significantly longer in the eribulin mesylate group than in the TPC group (median OS: 13.1 months vs. 10.6 months, hazard ratio [HR]: $0.81, p=0.041$ ). Furthermore, an updated analysis of OS confirmed the significant increase in OS of the eribulin mesylate group compared with the TPC group (median OS: 13.2 months vs. 10.5 months, HR: 0.81, $p=$ $0.014)$ [16].

Based on these results, the combination therapy of eribulin mesylate and trastuzumab was also expected to provide a superior antitumor effect and favorable safety profile.

Therefore, a phase 1 study of eribulin mesylate in combination with trastuzumab in Japanese patients with advanced or recurrent HER2+ breast cancer was carried out.

\section{Materials and methods}

Study design and treatment

This was a multi-center, open-label phase 1 study of eribulin mesylate with trastuzumab combination therapy in Japanese patients with advanced or recurrent HER2+ breast cancer (NCT01432886). This study consisted of Part 1 (weekly dose of trastuzumab) and Part 2 (tri-weekly dose of trastuzumab) to evaluate DLT, tolerability/safety, efficacy and PK, and to estimate the recommended dose of eribulin mesylate in this combination therapy.

Eribulin mesylate was administered by 2 - to 5 -minute i.v. injection on days 1 and 8 of a 21-day cycle. The initial dose of eribulin mesylate was $1.4 \mathrm{mg} / \mathrm{m}^{2}$ (equivalent to $1.23 \mathrm{mg}$ / $\mathrm{m}^{2}$ eribulin expressed as free base) in combination with trastuzumab treatment. Eribulin mesylate was administered on days 1 and 8 , if all of the following criteria were met: (1) neutrophil count $\geq 1.0 \times 10^{3} / \mu \mathrm{L}$, (2) platelet count $\geq 7.5 \times 10^{4} /$ $\mu \mathrm{L}$, and (3) non-hematologic toxicity $\leq$ grade 2 (except grade 3 nausea, vomiting, and diarrhea controllable with antiemetic or anti-diarrheal medication and abnormal laboratory parameters not requiring treatment). If the patient did not meet the criteria, the administration of the next dose was delayed. If the patient met the criteria within a 1-week delay, the 2nd administration of the cycle was implemented, and the next cycle had to be initiated no sooner than 2 weeks after the 2 nd administration. If the patient did not meet the criteria within a 1-week delay, the 2 nd administration was skipped. Dose reduction of eribulin mesylate could be exercised at the discretion of the investigator if the 2 nd administration in a cycle was delayed or skipped. If dose reduction was necessary, the $1.4 \mathrm{mg} / \mathrm{m}^{2}$ dose of eribulin mesylate was initially reduced to $1.1 \mathrm{mg} / \mathrm{m}^{2}$ and then further reduced to $0.7 \mathrm{mg} / \mathrm{m}^{2}$.

In Part 1, trastuzumab was administered by i.v. infusion at $4 \mathrm{mg} / \mathrm{kg}$ as a loading dose and at $2 \mathrm{mg} / \mathrm{kg}$ weekly. In Part 2, trastuzumab was administered by i.v. infusion at $8 \mathrm{mg} / \mathrm{kg}$ as a loading dose and at $6 \mathrm{mg} / \mathrm{kg}$ tri-weekly. The infusion time of trastuzumab was $90 \mathrm{~min}$ or longer at initial administration and could be shortened to $30 \mathrm{~min}$ from the $2 \mathrm{nd}$ administration and later. Trastuzumab was administered immediately after eribulin mesylate administration when used in the same day. Concomitant use of other medications or treatments was allowed. However, other anti-cancer drugs, investigational drugs and prophylactic administration of granulocyte-colony stimulating factor (G-CSF) were not permitted during the study.

DLT was evaluated in the first cycle, and if DLTs were observed in none or one of the first three patients, an additional three patients were to be added at the same dose level. If none or one of a total of six patients experienced a DLT, the investigated dose level of eribulin mesylate was to be regarded 
as tolerable with the trastuzumab combination. In the event that two of six patients reported a DLT, the investigators were to obtain written or verbal advice from an Independent Safety Committee on whether to investigate a decreased dose level of eribulin mesylate $\left(1.1 \mathrm{mg} / \mathrm{m}^{2}\right)$ as the initial dose. The initial eribulin mesylate dose level was planned to decrease to $1.1 \mathrm{mg} / \mathrm{m}^{2}$ if a DLT was reported in three or more patients. Patients were to continue to receive eribulin mesylate until they no longer received clinical benefit, had progressive disease (PD), or experienced unacceptable toxicity.

The protocol was approved by the Institutional Review Board and conducted in accordance with the Declaration of Helsinki.

Patient eligibility

Key inclusion criteria included: 20-74 years of age; histologically or cytologically confirmed advanced or recurrent breast cancer; HER2+ tumor score of 3+ by immunohistochemistry staining or gene amplification by fluorescence in situ hybridization (FISH); and any of the following, 1) evidence of recurrence during adjuvant chemotherapy with trastuzumab and taxane, 2) evidence of recurrence within 6 months after adjuvant chemotherapy with trastuzumab and taxane or 3) prior chemotherapy including trastuzumab and taxane for advanced or recurrent breast cancer; normal function in major organs; left ventricular ejection fraction (LVEF) $\geq 60 \%$ by multigated acquisition scan or echocardiogram (B or $\mathrm{M}$ mode); and Eastern Cooperative Oncology Group (ECOG) performance status of 0 or 1 .

Key exclusion criteria included: brain metastasis accompanied by clinical symptoms or requiring treatment; severe active infection requiring treatment; pleural effusions, ascites or pericardial effusions requiring drainage; pregnancy or breastfeeding; and refusal of supportive therapy by blood transfusion. All patients provided written informed consent prior to any study procedure.

\section{Assessments}

\section{DLTs}

The following toxicities were to be regarded as DLTs if they occurred in the first cycle and their causal relationship with the study treatment could not be ruled out: grade 4 neutropenia persistent for more than 7 days; grade 3 or above febrile neutropenia; grade 4 thrombocytopenia or grade 3 thrombocytopenia requiring blood transfusion; and non-hematologic toxicity $\geq$ grade 3 (unless grade 3 nausea, vomiting and diarrhea was controllable with an anti-emetic and anti-diarrheal medication, or clinical laboratory abnormalities did not require treatment). It would also be regarded as a DLT if the 2nd eribulin mesylate administration per cycle was delayed and the study treatment could not be resumed from day 22 of cycle 1 .

Safety

The demographic and disease characteristics of breast cancer were recorded at baseline and included HER2 status, estrogen receptor status, progesterone receptor status, and prior therapy complications. Safety assessments were made throughout the study. The factors that were assessed include adverse events (AEs), vital signs, bodyweight, 12-lead electrocardiogram, multigated acquisition scan or echocardiogram, concomitant medications, and clinical laboratory values (hematology, blood biochemistry and urinalysis). AEs were assessed on days 1,8 and 15 of each cycle. AE severity was classified according to the Japanese version of Common Terminology Criteria for Adverse Events v4.0. QT interval corrected for heart rate using Fridericia's formula (QTcF) and LVEF assessment were conducted before the treatment, on day 15 of cycle 1 , on day 1 of every 4 th cycle, and if clinically indicated.

PK and biochemical methodology

Blood samples were taken for eribulin PK analysis on days 1 and 8 of the first treatment cycle, pre-dose, end of infusion, $30 \mathrm{~min}$, and 1, 2, 4, 24, 72 and $168 \mathrm{~h}$ after drug administration. Plasma concentrations of eribulin, measured as the free-base (i.e. non-mesylate) equivalent, were determined by using the validated liquid chromatography- tandem mass spectrometry method. The lower limit of quantitation was $0.2 \mathrm{ng} / \mathrm{mL}$.

In Part 1, blood samples were taken for trastuzumab PK analysis on day 1 (pre-dose, end of infusion, and 3, 4, 24 and $72 \mathrm{~h}$ after drug administration) and day 8 and 15 (pre-dose) of cycle 1 , and on day 1 (pre-dose) of cycle 2 and later. In Part 2, blood samples of day 1 (pre-dose and 3, 4, 24, 72, 168 and $336 \mathrm{~h}$ after drug administration) of cycle 1 and day 1 (predose) of cycle 2 and later cycles were taken. Serum concentrations of trastuzumab were determined by using the validated enzyme-linked immunosorbent assay method. The lower limit of quantitation was $10 \mu \mathrm{g} / \mathrm{mL}$.

PK parameters for eribulin and trastuzumab were calculated by a non-compartmental approach by using WinNonlin software version 6.2 (Pharsight Corporation, CA, USA). The calculated parameters included: area under the curve extrapolated to infinity $\left(\mathrm{AUC}_{(0-\mathrm{inf})}\right)$, terminal half-life $\left(\mathrm{t}_{1 / 2}\right)$, total clearance $(\mathrm{CL})$ and volume of distribution at steady state $\left(\mathrm{V}_{\mathrm{ss}}\right)$. The maximum observed plasma concentration $\left(\mathrm{C}_{\max }\right)$ and time to $\mathrm{C}_{\max }\left(\mathrm{t}_{\max }\right)$ were directly derived from the data. 
Tumor assessment

Tumor response was assessed by the investigators according to the Response Evaluation Criteria in Solid Tumors (RECIST) version 1.1 [17]. Tumor assessments were performed within 28 days prior to the start of treatment, 6 weeks after the first dose and every 6 weeks thereafter, or sooner, if there was clinical suspicion of disease progression.

\section{Results}

Results are based on data collected until an August 2, 2013, cutoff date.

\section{Patient characteristics}

A total of 12 patients received eribulin mesylate and trastuzumab, 6 in Part 1 and 6 in Part 2. These patients were extensively pretreated with a median of 4.5 (range, 1-14) prior chemotherapy regimens. Patient demographics and baseline characteristics are shown in Table 1.
Treatment

For the overall population, eribulin mesylate and trastuzumab were administered for a median of 7 (range, 2-23) cycles, with eight patients receiving five or more cycles. The numbers of treatment cycles by patients are shown in Table 2 . Treatment was discontinued in seven patients $(58.3 \%)$ due to PD, and two patients $(16.7 \%)$ withdrew due to AEs. Three patients $(25.0 \%)$ continued to receive the study drug treatment at the time of the cutoff date. Dose adjustment (reduction, delay or skip) of eribulin mesylate occurred in ten patients $(83.3 \%)$; eight patients $(66.7 \%)$ had dose reduction, eight patients $(66.7 \%)$ had dose delay, and five patients $(41.7 \%)$ had to skip one dose per cycle.

\section{DLTs}

DLTs were evaluated on the first cycle, and none of the 12 patients experienced DLT. In cycle 1 , grade 3 or 4 neutropenia that led to a dose delay of the day 8 administration of eribulin mesylate occurred in two patients $(16.7 \%)$, and a dose was skipped in two patients $(16.7 \%)$. Two patients $(16.7 \%)$
Table 1 Patient demographics and baseline characteristics
ECOG Eastern Cooperative Oncology Group, ER estrogen receptor, $P R$ progesterone receptor

${ }^{a}$ Including the number of neoadjuvant, adjuvant and therapeutic therapy

\begin{tabular}{|c|c|c|c|}
\hline Parameter & Part $1(N=6)$ & Part $2(N=6)$ & Total $(N=12)$ \\
\hline Age, median (range), years & $64.5(58-72)$ & $47.0(39-64)$ & $60.0(39-72)$ \\
\hline \multicolumn{4}{|l|}{ Race, n (\%) } \\
\hline Japanese & 6 & 6 & $12(100.0)$ \\
\hline \multicolumn{4}{|l|}{ ECOG performance status, n (\%) } \\
\hline 0 & 3 & 2 & $5(41.7)$ \\
\hline 1 & 3 & 4 & $7(58.3)$ \\
\hline $\mathrm{ER}+$ and/or PR + disease, $\mathrm{n}(\%)$ & 2 & 3 & $5(41.7)$ \\
\hline \multicolumn{4}{|c|}{ Number of prior anti-cancer drug treatment, $\mathrm{n}(\%)^{\mathrm{a}}$} \\
\hline 1 & 0 & 1 & $1(8.3)$ \\
\hline 2 & 0 & 1 & $1(8.3)$ \\
\hline 3 & 2 & 0 & $2(16.7)$ \\
\hline 4 & 1 & 1 & $2(16.7)$ \\
\hline$\geq 5$ & 3 & 3 & $6(50.0)$ \\
\hline Median (range) & $5.0(3-14)$ & $4.5(1-6)$ & $4.5(1-14)$ \\
\hline Prior trastuzumab treatment, $\mathrm{n}(\%)$ & 6 & 6 & $12(100.0)$ \\
\hline \multicolumn{4}{|c|}{ Number of prior trastuzumab treatment, $\mathrm{n}(\%)^{\mathrm{a}}$} \\
\hline 1 & 2 & 1 & $3(25.0)$ \\
\hline 2 & 1 & 3 & $4(33.3)$ \\
\hline$\geq 3$ & 3 & 2 & $5(41.7)$ \\
\hline Median (range) & $2.5(1-5)$ & $2.0(1-4)$ & $2.0(1-5)$ \\
\hline Prior taxane treatment, $\mathrm{n}(\%)$ & 6 & 6 & $12(100.0)$ \\
\hline \multicolumn{4}{|l|}{ Number of prior taxane treatment, $\mathrm{n}(\%)^{\mathrm{a}}$} \\
\hline 1 & 3 & 4 & $7(58.3)$ \\
\hline 2 & 2 & 2 & $4(33.3)$ \\
\hline 3 & 1 & 0 & $1(8.3)$ \\
\hline Prior anthracycline treatment, $\mathrm{n}(\%)$ & 3 & 3 & $6(50.0)$ \\
\hline
\end{tabular}


Table 2 Numbers of treatment cycles by patients

\begin{tabular}{llll}
\hline $\begin{array}{l}\text { Number of cycles } \\
\text { received, n (\%) }\end{array}$ & Part 1 $(N=6)$ & Part 2 $(N=6)$ & Total $(N=12)$ \\
\hline $1-2$ & - & 1 & $1(8.3)$ \\
$3-4$ & 2 & 1 & $3(25.0)$ \\
$5-8$ & - & $3^{\mathrm{a}}$ & $3(25.0)^{\mathrm{a}}$ \\
$9-12$ & 2 & - & $2(16.7)$ \\
$13-16$ & - & $1^{\mathrm{a}}$ & $1(8.3)^{\mathrm{a}}$ \\
$17-20$ & - & - & - \\
$\geq 21$ & $2^{\mathrm{a}}$ & - & $2(16.7)^{\mathrm{a}}$ \\
\hline
\end{tabular}

${ }^{\text {a }} 3$ patients in total were on treatment as of 2 August 2013

received concomitant treatment with G-CSF for grade 4 neutropenia. The median time from day 1 of cycle 1 to the nadir in neutrophil count was 15 days (95 \% CI:14, 23), and the median time to recovery from the nadir to $\leq$ grade 2 neutropenia was 8 days (95\% CI: 4,9$)$. One of six patients (16.7\%) skipped a dose of trastuzumab due to an ejection fraction decreased (grade 2) in Part 1 (weekly dose of trastuzumab).

\section{Adverse events}

The AEs (all grades) experienced by $\geq 10 \%$ of patients and the total grade 3 or 4 AEs are shown in Table 3. The common AEs were similar in Part 1 and 2. Frequently observed hematologic AEs were neutropenia [100\% (grade 3/4: $100 \%$ )], leukopenia [100 \% (grade 3/4: $83 \%$ )] and anaemia [67\% (grade 3/4: $0 \%)$. G-CSF was administered to three patients $(25.0 \%)$. Frequently observed non-hematologic AEs, which were generally mild and manageable, included alopecia (67\%), pyrexia (42\%), decreased appetite (42\%) and rash (42\%) (all grade 1 or 2). Peripheral neuropathy occurred in four patients (33.3\%), including one patient $(8.3 \%)$ with grade 3 neuropathy. The AEs that led to study discontinuation were peripheral neuropathy in one patient $(8.3 \%)$ and tumour pain in one patient $(8.3 \%)$. An ejection fraction decreased (grade 2 ) occurred in two patients $(16.7 \%$ ) (both patients on day 15 of cycle 1 with one patient also in cycle 19), but the patients recovered after 1 week without treatment. The mean LVEF transition is shown in Fig. 1. The other cardiac disorders were second degree atrioventricular block (grade 2) in one patient $(8.3 \%)$ and palpitation (grade 1$)$ in two patients (16.7 \%); no treatments were required for these adverse advents. No grade 5 AEs or serious AEs were observed.

\section{PK}

Figure 2 shows the mean plasma eribulin concentration time profile up to $168 \mathrm{~h}$ and Table 4 shows the PK parameters of eribulin after eribulin mesylate $\left(1.4 \mathrm{mg} / \mathrm{m}^{2}\right)$ administration over 2 to 5 min with trastuzumab on day 1 of cycle 1 in Part 1 and Part 2, as well as previously reported phase 1 study results of eribulin mesylate monotherapy in Japanese patients [12].

In Part 1 , the mean values for $t_{1 / 2}, C L$ and $V_{s s}$ after administration of eribulin mesylate on day 1 (Table 4 ) and Day 8 were $38.1 \pm 7.80$ and $30.3 \pm 3.29 \mathrm{~h}, 2.47 \pm 0.774$ and $2.44 \pm 0.967 \mathrm{~L} / \mathrm{h} / \mathrm{m}^{2}$, and $101 \pm 45.3$ and $77.9 \pm 37.6 \mathrm{~L} / \mathrm{m}^{2}$, respectively. In Part 2, the mean values for $t_{1 / 2}, C L$ and $V_{s s}$ after administration of eribulin mesylate on day 1 (Table 4) and Day 8 were $35.0 \pm 10.8$ and $31.7 \pm 8.58 \mathrm{~h}, 2.12 \pm 0.754$ and $1.95 \pm 0.721 \mathrm{~L} / \mathrm{h} / \mathrm{m}^{2}$, and $69.8 \pm 11.8$ and $58.0 \pm 6.99 \mathrm{~L} / \mathrm{m}^{2}$, respectively.

After trastuzumab was administered intravenously in combination with eribulin, trastuzumab was eliminated from the serum biphasically after reaching the $\mathrm{C}_{\max }$ in both Part 1 and 2. In Part 1 , the mean values for $t_{1 / 2}, C L$ and $V_{s s}$ after administration of trastuzumab $(4 \mathrm{mg} / \mathrm{kg})$ on day 1 were 115 $\pm 28.0 \mathrm{~h}, 0.369 \pm 0.0297 \mathrm{~mL} / \mathrm{h} / \mathrm{kg}$ and $62.4 \pm 17.9 \mathrm{~mL} / \mathrm{kg}$, respectively. In Part 2 , the mean values of $\mathrm{t}_{1 / 2}, \mathrm{CL}$ and $\mathrm{V}_{\mathrm{ss}}$ after administration of trastuzumab $(8 \mathrm{mg} / \mathrm{kg})$ on day 1 were $173 \pm$ $26.7 \mathrm{~h}, 0.271 \pm 0.0343 \mathrm{~mL} / \mathrm{h} / \mathrm{kg}$ and $62.0 \pm 4.04 \mathrm{~mL} / \mathrm{kg}$, respectively (Table 5).

\section{Antitumor activity}

Tumor responses were evaluated by RECIST version 1.1 in all 12 patients. The ORR was $8.3 \%(95 \% \mathrm{CI}: 0.2,38.5)$ and tumor responses consisted of a partial response (PR) in one patient $(8.3 \%)$, stable disease (SD: including non-complete response $(\mathrm{CR}) /$ non-PD) $\geq 5$ weeks) in ten patients $(83.3 \%)$ and $\mathrm{PD}$ in one patient $(8.3 \%)$. The disease control rate $(\mathrm{CR}+$ $\mathrm{PR}+\mathrm{SD} \geq 11$ weeks) was $83.3 \%(95 \% \mathrm{CI}: 51.6,97.9)$ and the clinical benefit rate $(\mathrm{CR}+\mathrm{PR}+\mathrm{SD} \geq 23$ weeks) was $50.0 \%$ (95\% CI: 21.1, 78.9) (Table 6).

\section{Discussion}

This phase 1 study established the recommended dose of eribulin mesylate as $1.4 \mathrm{mg} / \mathrm{m}^{2}$ when administered on days 1 and 8 of a 21-day cycle with appropriate dose adjustment in combination with either weekly trastuzumab ( $4 \mathrm{mg} / \mathrm{kg}$ loading dose, $2 \mathrm{mg} / \mathrm{kg} /$ weekly) or tri-weekly trastuzumab $(8 \mathrm{mg} / \mathrm{kg}$ loading dose, $6 \mathrm{mg} / \mathrm{kg} /$ tri-weekly) in Japanese patients with advanced or recurrent HER2+ breast cancer. Eribulin mesylate was suggested to be safe and tolerable in combination with trastuzumab with the same recommended dose as monotherapy [12].

There were no DLTs, grade 5 AEs or serious AEs in this study. The most common AEs of grade 3 or 4 reported in this study were neutropenia and leukopenia, which were 
Table 3 Adverse events (All grades in $\geq 10 \%$ of patients and grades $3 / 4$ in total)

\begin{tabular}{|c|c|c|c|c|c|c|}
\hline & \multicolumn{2}{|l|}{ Part 1} & \multicolumn{2}{|l|}{ Part 2} & \multicolumn{2}{|l|}{ Total } \\
\hline & All grades & Grade 3/4 AEs & All grades & Grade $3 / 4$ AEs & All grades & Grade $3 / 4$ AEs \\
\hline AE preferred term & $N=6$ & $N=6$ & $N=6$ & $N=6$ & $N=12$ & $N=12$ \\
\hline \multicolumn{7}{|l|}{ Blood and lymphatic system disorders } \\
\hline Neutropenia & 6 & 6 & 6 & 6 & $12(100.0)$ & $12(100.0)$ \\
\hline Leukopenia & 6 & 4 & 6 & 6 & $12(100.0)$ & $10(83.3)$ \\
\hline Anaemia & 4 & 0 & 4 & 0 & $8(66.7)$ & 0 \\
\hline Lymphopenia & 0 & 0 & 3 & 3 & $3(25.0)$ & $3(25.0)$ \\
\hline Febrile neutropenia & 0 & 0 & 1 & 1 & $1(8.3)$ & $1(8.3)$ \\
\hline \multicolumn{7}{|l|}{ Cardiac disorders } \\
\hline Palpitations & 2 & 0 & 0 & 0 & $2(16.7)$ & 0 \\
\hline \multicolumn{7}{|l|}{ Gastrointestinal disorders } \\
\hline Nausea & 1 & 0 & 2 & 0 & $3(25.0)$ & 0 \\
\hline Vomiting & 0 & 0 & 3 & 0 & $3(25.0)$ & 0 \\
\hline Constipation & 2 & 0 & 0 & 0 & $2(16.7)$ & 0 \\
\hline Stomatitis & 1 & 0 & 1 & 0 & $2(16.7)$ & 0 \\
\hline \multicolumn{7}{|c|}{ General disorders and administration site conditions } \\
\hline Pyrexia & 2 & 0 & 3 & 0 & $5(41.7)$ & 0 \\
\hline Malaise & 3 & 0 & 0 & 0 & $3(25.0)$ & 0 \\
\hline Chest discomfort & 1 & 0 & 1 & 0 & $2(16.7)$ & 0 \\
\hline Injection site reaction & 2 & 0 & 0 & 0 & $2(16.7)$ & 0 \\
\hline \multicolumn{7}{|l|}{ Infections and infestations } \\
\hline Lung infection & 0 & 0 & 2 & 0 & $2(16.7)$ & 0 \\
\hline Tonsillitis & 1 & 0 & 1 & 0 & $2(16.7)$ & 0 \\
\hline \multicolumn{7}{|l|}{ Investigations } \\
\hline Alanine aminotransferase increased & 2 & 0 & 1 & 0 & $3(25.0)$ & 0 \\
\hline Aspartate aminotransferase increased & 2 & 0 & 1 & 0 & $3(25.0)$ & 0 \\
\hline Blood creatine phosphokinase increased & 3 & 0 & 0 & 0 & $3(25.0)$ & 0 \\
\hline Ejection fraction decreased & 1 & 0 & 1 & 0 & $2(16.7)$ & 0 \\
\hline \multicolumn{7}{|l|}{ Metabolism and nutrition disorders } \\
\hline Decreased appetite & 4 & 0 & 1 & 0 & $5(41.7)$ & 0 \\
\hline Hypertriglyceridaemia & 1 & 1 & 2 & 2 & $3(25.0)$ & $3(25.0)$ \\
\hline Hypophosphataemia & 0 & 0 & 1 & 1 & $1(8.3)$ & $1(8.3)$ \\
\hline \multicolumn{7}{|l|}{ Musculoskeletal and connective tissue disorders } \\
\hline Myalgia & 4 & 0 & 0 & 0 & $4(33.3)$ & 0 \\
\hline Muscle spasms & 2 & 0 & 0 & 0 & $2(16.7)$ & 0 \\
\hline \multicolumn{7}{|l|}{ Nervous system disorders } \\
\hline Dysgeusia & 2 & 0 & 2 & 0 & $4(33.3)$ & 0 \\
\hline${ }^{\mathrm{a}}$ Peripheral neuropathy & 4 & 1 & 0 & 0 & $4(33.3)$ & $1(8.3)$ \\
\hline Headache & 0 & 0 & 2 & 0 & $2(16.7)$ & 0 \\
\hline \multicolumn{7}{|l|}{ Skin and subcutaneous tissue disorders } \\
\hline Alopecia & 5 & - & 3 & - & $8(66.7)$ & - \\
\hline Rash & 4 & 0 & 1 & 0 & $5(41.7)$ & 0 \\
\hline
\end{tabular}

${ }^{\text {a }}$ Peripheral neuropathy includes neuropathy peripheral and peripheral sensory neuropathy in preferred terms

hematologic toxicities also found in prior clinical studies of eribulin mesylate monotherapy in Japanese patients $[12,13]$. All 12 patients experienced neutropenia, but all events were reversible and easily managed with appropriate dose reduction or a skipped dose. The median time of 8 days required for resolution from nadir in neutrophil count to $\leq$ grade 2 neutropenia in cycle 1 and the low requirement for G-CSF use (25\%) supported the safety of the defined eribulin mesylate 


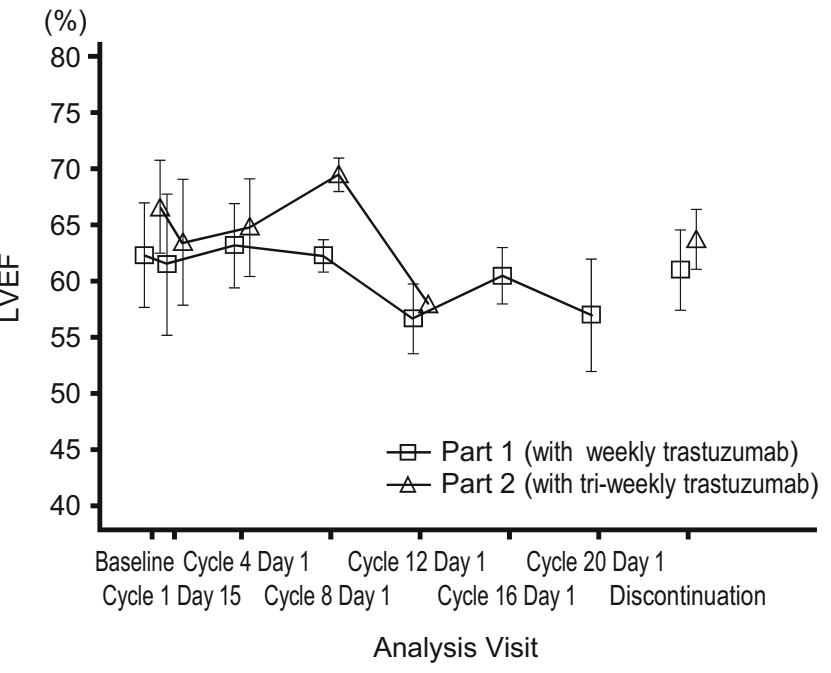

Fig. 1 Mean LVEF transition assessed by echocardiogram: Assessment by $\mathrm{B}$ mode echocardiogram at the indicated times. Baseline LVEF was $\geq 60 \%$ by $\mathrm{B}$ or $\mathrm{M}$ mode echocardiogram in all patients, as defined in the inclusion criteria

administration procedure. The non-hematologic AEs were consistent with the known safety profile of eribulin, with only one grade 3 or higher AE with clinical symptoms (grade 3 peripheral neuropathy). The low incidence of neuropathy was consistent with previous eribulin mesylate studies and the incidence was also lower when compared with taxane studies $[12-16,18]$.

A retrospective review of seven phase 2 and phase 3 trastuzumab clinical trials reported that the patients treated with trastuzumab were at an increased risk of cardiac dysfunction. The incidence of cardiac dysfunction was highest in patients receiving concomitant trastuzumab and anthracycline/ cyclophosphamide ( $27 \%)$. The risk was substantially lower

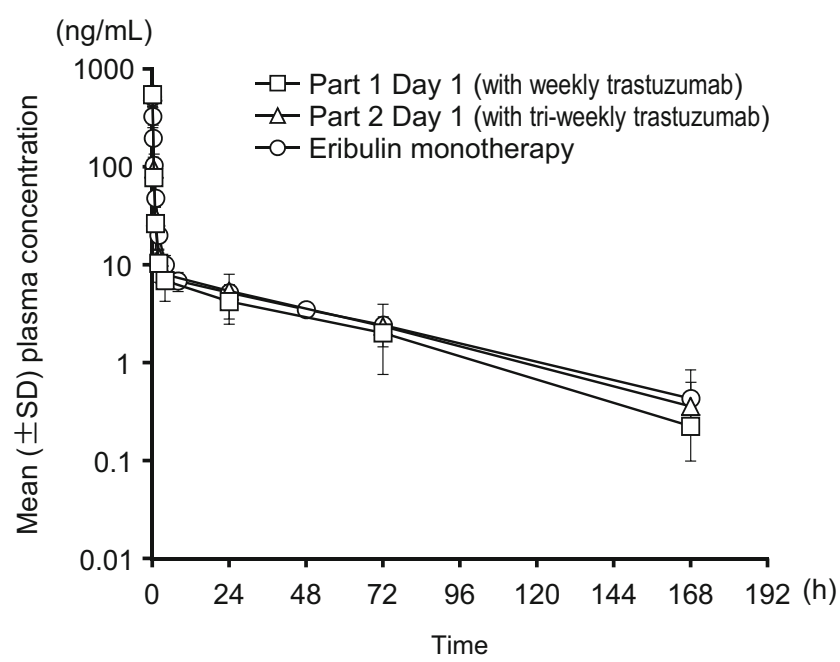

Fig. 2 PK analysis of the relationship between mean plasma eribulin concentration versus time profiles for Parts 1 and 2 of the study and for a previous phase 1 study [12] (cycle 1, day 1)
Table 4 Pharmacokinetic parameters of eribulin (cycle 1, day 1)

\begin{tabular}{lcll}
\hline PK Parameter (unit) & Part 1 $(n=6)$ & Part 2 $(n=6)$ & Monotherapy $(n=6)$ \\
\hline $\mathrm{C}_{\max }(\mathrm{ng} / \mathrm{mL})$ & $547 \pm 128$ & $582 \pm 61.0$ & $519.4 \pm 107.2$ \\
$\mathrm{AUC}_{(0-\text { inf }}(\mathrm{ng} \cdot \mathrm{h} / \mathrm{mL})$ & $524 \pm 137$ & $631 \pm 271$ & $672.7 \pm 113.7$ \\
$\mathrm{t}_{1 / 2}(\mathrm{~h})$ & $38.1 \pm 7.80$ & $35.0 \pm 10.8$ & $39.4 \pm 8.3$ \\
$\mathrm{CL}\left(\mathrm{L} / \mathrm{h} / \mathrm{m}^{2}\right)$ & $2.47 \pm 0.774$ & $2.12 \pm 0.754$ & $1.89 \pm 0.33$ \\
$\mathrm{~V}_{\mathrm{ss}}\left(\mathrm{L} / \mathrm{m}^{2}\right)$ & $101 \pm 45.3$ & $69.8 \pm 11.8$ & $76.3 \pm 19.2$ \\
\hline
\end{tabular}

Mean \pm SD

$A U C_{(0-i n f)}$ area under the concentration-time curve from time zero to infinity, $C L$ total clearance, $C_{\max }$ maximum plasma concentration, $t_{1 / 2}$ terminal half-life, $V_{S S}$ steady-state volume of distribution

in patients receiving paclitaxel and trastuzumab (13\%), trastuzumab alone (3 to $7 \%$ ), anthracycline/ cyclophosphamide alone $(8 \%)$, or paclitaxel alone $(1 \%)$ [19]. To evaluate the risk of cardiac dysfunction in patients receiving the combination therapy of eribulin mesylate and trastuzumab, periodic assessments of QTcF and LVEF were conducted. Although an ejection fraction decreased (grade 2) was observed in two patients (16.7\%), these patients recovered after 1 week without treatment. The mean LVEF transition was $\geq 55 \%$ in either part 1 or 2 of the study (Fig. 1). The other cardiac disorders experienced by patients were second-degree atrioventricular block and palpitation, which did not require treatment. Therefore, a clear increased risk of severe cardiac dysfunction resulting from the addition of eribulin mesylate to trastuzumab was not suggested from this study. Since a few cardiac events were observed, cardiac function should be routinely assessed in patients receiving eribulin mesylate in combination with trastuzumab, which is consistent with the recommendation for patients receiving trastuzumab in other combination therapies. The neutropenia observed was manageable, and the non-hematologic AEs were generally mild. Thus, treatment with eribulin mesylate $\left(1.4 \mathrm{mg} / \mathrm{m}^{2}\right)$ on days 1 and 8 of a 21-day cycle with appropriate dose adjustment was regarded as tolerable in combination with trastuzumab (either weekly or tri-weekly) in Japanese patients.

Table 5 Pharmacokinetic parameters of trastuzumab (cycle 1, day 1)

\begin{tabular}{lcc} 
PK parameter (unit) & Part 1 $(4 \mathrm{mg} / \mathrm{kg})(n=6)$ & Part 2 $(8 \mathrm{mg} / \mathrm{kg})(n=6)$ \\
\hline $\mathrm{C}_{\max }(\mu \mathrm{g} / \mathrm{mL})$ & $74.9 \pm 25.9$ & $194 \pm 33.1$ \\
$\mathrm{AUC}(\mu \mathrm{g} \cdot \mathrm{h} / \mathrm{mL})$ & $10900 \pm 868$ & $29800 \pm 3740$ \\
$\mathrm{t}_{1 / 2}(\mathrm{~h})$ & $115 \pm 28.0$ & $173 \pm 26.7$ \\
$\mathrm{CL}(\mathrm{mL} / \mathrm{h} / \mathrm{kg})$ & $0.369 \pm 0.0297$ & $0.271 \pm 0.0343$ \\
$\mathrm{~V}_{\mathrm{ss}}(\mathrm{mL} / \mathrm{kg})$ & $62.4 \pm 17.9$ & $62.0 \pm 4.04$ \\
\hline
\end{tabular}

Mean \pm SD

$A U C_{(0-\text {-inf })}$ area under the concentration-time curve from time zero to infinity, $C L$ total clearance, $C_{\max }$ maximum plasma concentration, $t_{1 / 2}$ terminal half-life, $V_{S S}$ steady-state volume of distribution 
Table 6 Best tumor responses

$C I$ confidence interval, $C R$ complete response, $P R$ partial response, $S D$ stable disease, $P D$ progressive disease

\begin{tabular}{lllc}
\hline & Part 1 & Part 2 & Total \\
\hline Response category, n (\%) & $N=6$ & $N=6$ & $N=12$ \\
Best tumor response, n (\%) & & & \\
CR & 0 & 0 & 0 \\
PR & $1(16.7)$ & 0 & $1(8.3)$ \\
SD (including non-CR/non-PD) & $4(66.7)$ & $6(100.0)$ & $10(83.3)$ \\
PD & $1(16.7)$ & 0 & $1(8.3)$ \\
Not evaluable & 0 & 0 & 0 \\
Objective response rate & $1(16.7)$ & 0 & $1(8.3)$ \\
$95 \%$ CI & $0.4,64.1$ & $0.0,45.9$ & $0.2,38.5$ \\
Disease Control Rate & $5(83.3)$ & $5(83.3)$ & $10(83.3)$ \\
$95 \%$ CI & $35.9,99.6$ & $35.9,99.6$ & $51.6,97.9$ \\
Clinical Benefit Rate & $4(66.7)$ & $2(33.3)$ & $6(50.0)$ \\
$95 \%$ CI & $22.3,95.7$ & $4.3,77.7$ & $21.1,78.9$ \\
\hline
\end{tabular}

The PK profile of eribulin in combination with trastuzumab was similar between the present study and the previously reported phase 1 study of eribulin mesylate monotherapy in Japanese patients [12], including the mean $t_{1 / 2}$, volume of distribution, and renal and systemic clearance (Fig. 2, Table 4), and as in those studies, the parameters were consistent between days 1 and 8 of the first cycle. The PK profile of trastuzumab (Table 5) was also similar to that in the previous reported phase 1 study of trastuzumab [20]. Combination therapy of trastuzumab with eribulin mesylate did not appear to change the PK profile of either eribulin or trastuzumab. Therefore, no pharmacokinetic drug-drug interaction between eribulin and trastuzumab was indicated.

Although efficacy was not a primary objective, 8 of 12 patients completed more than 5 cycles of treatment and the clinical benefit rate (CBR) was $50.0 \%$ (95\% CI: 21.1, 78.9), which also supports the long-term efficacy and safety of this combination therapy. Recently, the final results of a phase 2 study of eribulin mesylate $\left(1.4 \mathrm{mg} / \mathrm{m}^{2}\right)$ in combination with trastuzumab $(8 \mathrm{mg} / \mathrm{kg}$ as a loading dose followed by a $6 \mathrm{mg} / \mathrm{kg}$ tri-weekly dose) as a first-line therapy for locally recurrent or metastatic HER2+ breast cancer was reported. Those results showed: ORR of $71.2 \%$ (37/52 patients), CBR of $84.6 \%$ (95\% CI: 71.9, 93.1), median progression free survival of 11.6 months (95 \% CI: 9.1, 13.9) and an acceptable safety profile. The most common AEs of grade 3 or 4 were neutropenia $(38.5 \%)$ with clinical laboratory hematologic abnormalities of neutrophils $(55.8 \%)$ and peripheral neuropathy (26.9\%) [21]. The low incidence of severe neutropenia compared with that of the present study $(100 \%)$ was considered to be due to the difference of prior chemotherapy regimen numbers. The high incidence of severe peripheral neuropathy compared with that of the present study $(8.3 \%)$ was likely due to the prolonged duration of treatment in a first-line setting.
In conclusion, $1.4 \mathrm{mg} / \mathrm{m}^{2}$ eribulin mesylate administered on days 1 and 8 of a 21-day cycle in combination with either weekly or tri-weekly trastuzumab was well tolerated in extensively pre-treated Japanese patients with advanced or recurrent HER2+ breast cancer. The safety profile shown in the present study and the reported phase 2 study [21] indicates that further evaluation of eribulin mesylate and trastuzumab combination therapy is warranted.

Acknowledgments We gratefully acknowledge the commitment of participating patients, their families, and the study investigators for their invaluable contribution to this research.

Ethical standards The protocol was approved by the Institutional Review Board and conducted in accordance with the Declaration of Helsinki.

Conflict of interest Hirofumi Mukai received lecture fees from Eisai Co., Ltd., AstraZeneca K.K., Chugai Pharmaceutical Co., Ltd., Daiichi Sankyo Co., Ltd., Sanofi K.K., and Taiho Pharmaceutical Co., Ltd. Toshiaki Saeki received lecture fees from Eisai Co., Ltd., AstraZeneca K.K., Bayer Yakuhin, Ltd., Chugai Pharmaceutical Co., Ltd., Fuji Pharma Co., Ltd., Kyowa Hakko Kirin Co., Ltd., Mochida Pharmaceutical Co., Ltd., Novartis Pharma K.K., Ono Pharmaceutical Co., Ltd., Pfizer Japan Inc., Sanofi K.K. and Taiho Pharmaceutical Co., Ltd. Yasutsuna Sasaki received lecture fees from Eisai Co., Ltd. and Chugai Pharmaceutical Co., Ltd. Hirofumi Mukai, Yoichi Naito and Nobuaki Matsubara received research funding from Eisai Co., Ltd., Chugai Pharmaceutical Co., Ltd., Daiichi Sankyo Co., Ltd., Glaxo SmithKline K.K., Nippon Boehringer Ingelheim Co., Ltd., Nippon Kayaku Co., Ltd., Novartis Pharma K.K., Phizer Japan Inc. and the Public Health Research Foundation. Toshiaki Saeki received research funding from Eisai Co., Ltd., Chugai Pharmaceutical Co., Ltd., Daiichi Sankyo Co., Ltd., Kyowa Hakko Kirin Co., Ltd., Novartis Pharma K.K., Ono Pharmaceutical Co., Ltd., Taiho Pharmaceutical Co., Ltd., Takeda Pharmaceutical Company Limited. Yasutsuna Sasaki received research funding from Eisai Co., Ltd. and Chugai Pharmaceutical Co., Ltd. Tadashi Nakanishi and Hiroshi Obaishi are employees and own stock of Eisai Co., Ltd. Masayuki Namiki is an employee of Eisai Co., Ltd. Ken Shimada has no disclosures. The study was designed under the responsibility of Eisai Co., Ltd.; The study was funded by Eisai Co., Ltd.; Eribulin mesylate was provided by Eisai Co., 
Ltd.; Eisai Co., Ltd. collected and analyzed the data and contributed to the interpretation of the study. All authors had full access to all of the data in the study and had final responsibility for the decision to submit for publication.

Open Access This article is distributed under the terms of the Creative Commons Attribution License which permits any use, distribution, and reproduction in any medium, provided the original author(s) and the source are credited.

\section{References}

1. Slamon DJ, Godolphin W, Jones LA, Holt JA, Wong SG, Keith DE, Levin WJ, Stuart SG, Udove J, Ullrich A et al (1989) Studies of the HER-2/neu proto-oncogene in human breast and ovarian cancer. Science 244:707-712

2. Slamon DJ, Clark GM, Wong SG, Levin WJ, Ullrich A, McGuire WL (1987) Human breast cancer: correlation of relapse and survival with amplification of the HER-2/neu oncogene. Science 235:177-182

3. Vogel CL, Cobleigh MA, Tripathy D, Gutheil JC, Harris LN, Fehrenbacher L, Slamon DJ, Murphy M, Novotny WF, Burchmore M, Shak S, Stewart SJ, Press M (2002) Efficacy and safety of trastuzumab as a single agent in first-line treatment of HER2overexpressing metastatic breast cancer. J Clin Oncol 20:719-726

4. Cobleigh MA, Vogel CL, Tripathy D, Robert NJ, Scholl S, Fehrenbacher L, Wolter JM, Paton V, Shak S, Lieberman G, Slamon DJ (1999) Multinational study of the efficacy and safety of humanized anti-HER2 monoclonal antibody in women who have HER2-overexpressing metastatic breast cancer that has progressed after chemotherapy for metastatic disease. J Clin Oncol 17:2639 2648

5. Slamon DJ, Leyland-Jones B, Shak S, Fuchs H, Paton V, Bajamonde A, Fleming T, Eiermann W, Wolter J, Pegram M, Baselga J, Norton L (2001) Use of chemotherapy plus a monoclonal antibody against HER2 for metastatic breast cancer that overexpresses HER2. N Engl J Med 344:783-792

6. Baselga J, Carbonell X, Castañeda-Soto NJ, Clemens M, Green M, Harvey V, Morales S, Barton C, Ghahramani P (2005) Phase II study of efficacy, safety, and pharmacokinetics of trastuzumab monotherapy administered on a 3-weekly schedule. J Clin Oncol 23:2162-2171

7. Leyland-Jones B, Gelmon K, Ayoub JP, Arnold A, Verma S, Dias R, Ghahramani P (2003) Pharmacokinetics, safety, and efficacy of trastuzumab administered every three weeks in combination with paclitaxel. J Clin Oncol 21:3965-3971

8. Bullock K, Blackwell K (2008) Clinical efficacy of taxanetrastuzumab combination regimens for HER-2-positive metastatic breast cancer. Oncologist 13:515-525. doi:10.1634/theoncologist. 2007-0204

9. Redana S, Donadio M, Nolè F, Jacomuzzi ME, Beano A, Martinello R, Sapino A, Viale G, Aglietta M, Montemurro F (2010) Trastuzumab with either docetaxel or vinorelbine as first-line treatment for patients with HER2-positive advanced breast cancer: a retrospective comparison. BMC Cancer 10:28. doi:10.1186/14712407-10-28

10. Kuznetsov G, Towle MJ, Cheng H, Kawamura T, TenDyke K, Liu D, Kishi Y, Yu MJ, Littlefield BA (2004) Induction of morphological and biochemical apoptosis following prolonged mitotic blockage by halichondrin B macrocyclic ketone analog E7389. Cancer Res 64: 5760-5766

11. Towle MJ, Salvato KA, Budrow J, Wels BF, Kuznetsov G, Aalfs KK, Welsh S, Zheng W, Seletsky BM, Palme MH, Habgood GJ, Singer LA, Dipietro LV, Wang Y, Chen JJ, Quincy DA, Davis A, Yoshimatsu K, Kishi Y, Yu MJ, Littlefield BA (2001) In vitro and in vivo anticancer activities of synthetic macrocyclic ketone analogues of halichondrin B. Cancer Res 61:1013-1021

12. Mukohara T, Nagai S, Mukai H, Namiki M, Minami H (2012) Eribulin mesylate in patients with refractory cancers: a Phase I study. Investig New Drugs 30:1926-1933. doi:10.1007/s10637-011-97412

13. Aogi K, Iwata H, Masuda N, Mukai H, Yoshida M, Rai Y, Taguchi K, Sasaki Y, Takashima S (2012) A phase II study of eribulin in Japanese patients with heavily pretreated metastatic breast cancer. Ann Oncol 23:1441-1448. doi:10.1093/annonc/mdr444

14. Vahdat LT, Pruitt B, Fabian CJ, Rivera RR, Smith DA, Tan-Chiu E, Wright J, Tan AR, Dacosta NA, Chuang E, Smith J, O'Shaughnessy J, Shuster DE, Meneses NL, Chandrawansa K, Fang F, Cole PE, Ashworth S, Blum JL (2009) Phase II study of eribulin mesylate, a halichondrin B analog, in patients with metastatic breast cancer previously treated with an anthracycline and a taxane. J Clin Oncol 27:2954-2961. doi:10.1200/JCO.2008.17.7618

15. Cortes J, Vahdat L, Blum JL, Twelves C, Campone M, Roché H, Bachelot T, Awada A, Paridaens R, Goncalves A, Shuster DE, Wanders J, Fang F, Gurnani R, Richmond E, Cole PE, Ashworth S, Allison MA (2010) Phase II study of the halichondrin B analog eribulin mesylate in patients with locally advanced or metastatic breast cancer previously treated with an anthracycline, a taxane, and capecitabine. J Clin Oncol 28:3922-3928. doi:10.1200/JCO. 2009.25.8467

16. Cortes J, O'Shaughnessy J, Loesch D, Blum JL, Vahdat LT, Petrakova K, Chollet P, Manikas A, Diéras V, Delozier T, Vladimirov V, Cardoso F, Koh H, Bougnoux P, Dutcus CE, Seegobin S, Mir D, Meneses N, Wanders J, Twelves C (2011) Eribulin monotherapy versus treatment of physician's choice in patients with metastatic breast cancer (EMBRACE): a phase 3 open-label randomised study. Lancet 377:914-923. doi:10.1016/ S0140-6736(11)60070-6

17. Eisenhauer EA, Therasse P, Bogaerts J, Schwartz LH, Sargent D, Ford R, Dancey J, Arbuck S, Gwyther S, Mooney M, Rubinstein L, Shankar L, Dodd L, Kaplan R, Lacombe D, Verweij J (2009) New response evaluation criteria in solid tumours: revised RECIST guideline (version 1.1). Eur J Cancer 45:228-247. doi:10.1016/j.ejca.2008. 10.026

18. Markman M (2003) Management of toxicities associated with the administration of taxanes. Expert Opin Drug Saf 2:141-146

19. Seidman A, Hudis C, Pierri MK, Shak S, Paton V, Ashby M, Murphy M, Stewart SJ, Keefe D (2002) Cardiac dysfunction in the trastuzumab clinical trials experience. J Clin Oncol 20:1215-1221

20. Tokuda Y, Watanabe T, Omuro Y, Ando M, Katsumata N, Okumura A, Ohta M, Fujii H, Sasaki Y, Niwa T, Tajima T (1999) Dose escalation and pharmacokinetic study of a humanized anti-HER2 monoclonal antibody in patients with HER2/neu-overexpressing metastatic breast cancer. Br J Cancer 81:1419-1425

21. Wilks S, Puhalla S, O'Shaughnessy J, Schwartzberg L, Berrak E, Song J, Cox D, Vahdat L (2014) Phase 2, multicenter, single-arm study of eribulin mesylate with trastuzumab as first-line therapy for locally recurrent or metastatic HER2-positive breast cancer. Clin Breast Cancer. doi:10.1016/j.clbc.2014.04.004 